\title{
ANALISIS DAN PERANCANGAN SISTEM MANAJEMEN KLAIM BERBASIS WEB DAN APLIKASI BLACKBERRY ${ }^{\circledR}$
}

\author{
Bayu Kanigoro; Andy Wijaya; C. N. Firmana; Astari Jusman \\ Computer Science Department, School of Computer Science, Binus University \\ Jl. K. H. Syahdan No. 9 Palmerah Jakarta Barat 11480 \\ bkanigoro@binus.edu
}

\begin{abstract}
Web and mobile technology help a lot of business activities since it can be accessed from the Internet and intranet networks so that flow of the information needed can reach out various locations. Web and mobile technology combined with E-CRM technology like helpdesk can be used to improve services. This study aims to design a web-based claim management system (supported with helpdesk system) and its BlackBerry ${ }^{\circledR}$ application for PT. Hoppecke Indonesia. An analysis through literature study and field survey (interview to the employees of PT. Hoppecke Indonesia) is implemented in this study based on the incremental method. The result achieved is a design web-based claims management system and the BlackBerry ${ }^{\circledR}$ application. The design is expected to maintain the relationship between customers and companies, especially in term of item maintenance and to make easy for customers to obtain information that will lead to loyalty to the company. Plus, the documentation of each interaction between customer and the company can be recorded properly.
\end{abstract}

Keywords: claim management system, helpdesk, BlackBerry ${ }^{\circledR}$ application, interaction between customer and company, documentation

\begin{abstract}
ABSTRAK
Teknologi web dan mobile membantu banyak kegiatan bisnis dan usaha karena dapat diakses dari jaringan Internet dan intranet sehingga pergerakan informasi yang dibutuhkan bisa menjangkau ke berbagai lokasi. Teknologi web dan mobile yang dipadukan dengan teknologi E-CRM berbentuk helpdesk dapat digunakan untuk meningkatkan pelayanan. Penelitian ini bertujuan merancang sistem manajemen klaim berbasis web (yang didukung sistem helpdesk) dan aplikasi BlackBerry ${ }^{\circledR}$ pada PT. Hoppecke Indonesia. Metodologi yang digunakan adalah analisis melalui studi pustaka dan survei lapangan (wawancara kepada karyawan-karyawan PT. Hoppecke Indonesia) berdasarkan metode inkremental. Hasil yang dicapai adalah suatu rancangan sistem manajemen klaim berbasis web dan aplikasi BlackBerry ${ }^{\circledR}$. Perancangan ini diharapkan dapat menjaga hubungan antara pelanggan dan perusahaan terutama dalam hal pemeliharaan barang yang ada di pelanggan serta mempermudah pelanggan mendapatkan informasi, sehingga pelanggan semakin loyal terhadap perusahaan. Selain itu dokumentasi antar interaksi dapat tercatat dengan baik.
\end{abstract}

Kata kunci: sistem manajemen klaim, helpdesk, aplikasi BlackBerry ${ }^{\circledR}$, interaksi, dokumentasi 


\section{PENDAHULUAN}

Teknologi web dan mobile membantu banyak kegiatan bisnis dan usaha dalam suatu organisasi perusahaan yang sudah menerapkan sistem informasi. Satu aplikasi bisnis yang menerapkan teknologi tersebut tidak harus dijalankan di standalone komputer yang berada di kantor tetapi bisa diakses dari jaringan Internet dan intranet sehingga pergerakan informasi yang dibutuhkan perusahaan dan pelanggan bisa menjangkau ke lokasi manapun selama masih dalam jangkauan jaringan internet. Dengan teknologi web dan mobile yang dipadukan dengan teknologi E-CRM berbentuk helpdesk, perusahaan dapat meningkatkan pelayanan dengan lebih maksimal.

E-CRM adalah customer relationship management yang memanfaatkan proses bisnis dan datadata secara online. E-CRM secara konsisten mengatur pribadi relevan dan interaksi produktif, bermakna untuk membangun hubungan yang sukses dengan pelanggan, penjual, karyawan, investor, dan yang lainnya menggunakan teknologi baru (Turban et.al, 2006, p.320).

Saat ini PT. Hoppecke Indonesia masih menggunakan proses penanganan klaim manual dengan menggunakan kertas dan tinta. Perusahaan dan klien merasakan proses klaim menjadi cukup lama dengan meningkatnya jumlah klaim. Dengan melihat kapasitas dan kemampuan teknologi ECRM, PT. Hoppecke Indonesia berencana untuk meningkatkan kecepatan pelayanan proses klaim dan tindakan kepada kliennya menggunakan teknologi web dan aplikasi BlackBerry ${ }^{\circledR}$. Tulisan ini membahas pembuatan sistem pelayanan klaim dengan menggunakan teknologi web dan BlackBerry ${ }^{\circledR}$ untuk pelayanan klaim pada PT. Hoppecke Indonesia menggunakan model incremental. Diharapkan hasilnya dapat meningkatkan kecepatan proses klaim dan tindakan terhadap kliennya.

\section{METODE}

Perancangan sistem managemen klaim ini menggunakan model incremental (Gambar 1). Menurut Pressman (2002, pp.45-47), model inkremental menggabungkan elemen-elemen model sekuensial linier (diaplikasikan secara berulang) dengan filosofi prototipe iterative. Model pertambahan memakai urutan-urutan linear di dalam model yang membingungkan, seiring dengan laju waktu kalender. Setiap urutan linier menghasilkan pertambahan, perangkat lunak "yang bisa disampaikan”.

\section{HASIL DAN PEMBAHASAN}

\section{Analisis Sistem yang Ada}

Berdasarkan data yang diambil menggunakan metode analisis studi pustaka dan survei lapangan (wawancara), secara garis besar sistem yang sedang berjalan adalah sebagai berikut. Pertama-tama, pelanggan yang mengajukan klaim menghubungi pegawai klaim. Kemudian, pegawai klaim mencatat nama telepon dan garis besar permasalahan pada pre-claim form. Pegawai klaim akan menghubungi kembali pelanggan tersebut sesuai dengan keterangan claim form. Claim form akan dikirimkan dalam bentuk hardcopy melalui fax. Selanjutnya pelanggan akan mengisi form tersebut dan mengirimkan kembali melalui fax. Bila pelanggan ingin mengecek perkembangan dari klaimnya, mereka harus menghubungi dan menanyakan langsung pada pegawai klaim yang bersangkutan. Sistem ini terangkum dalam Gambar 2. 


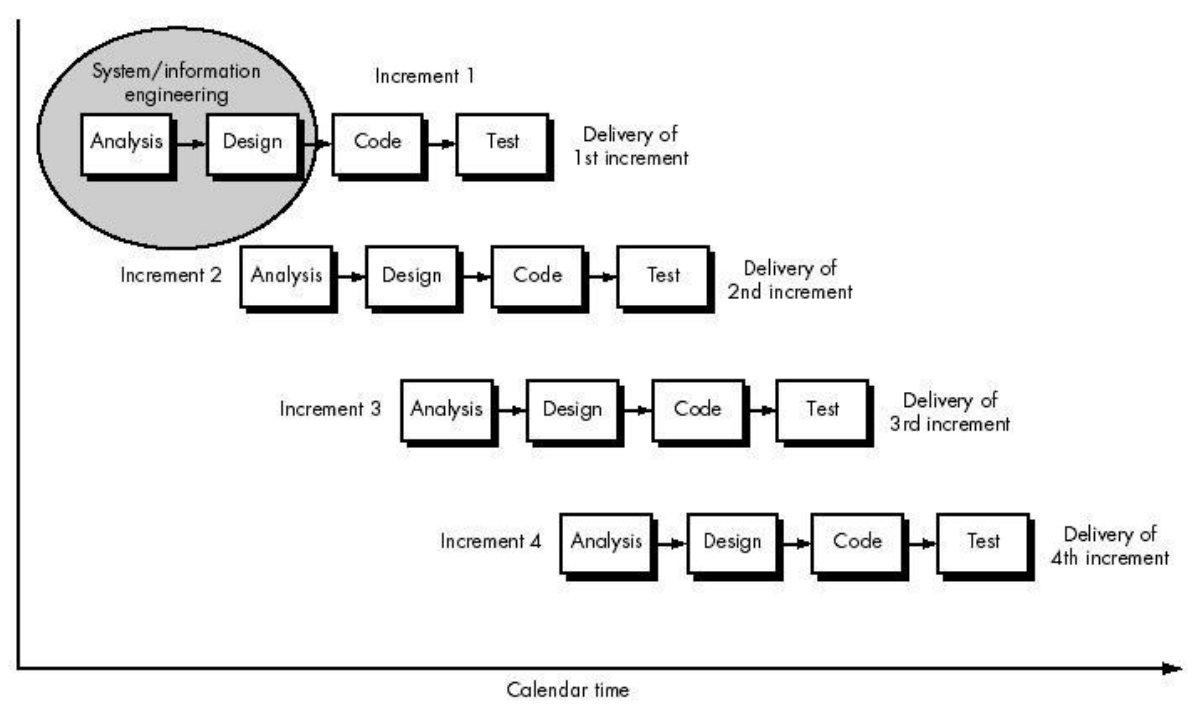

Gambar 1. Model inkremental.

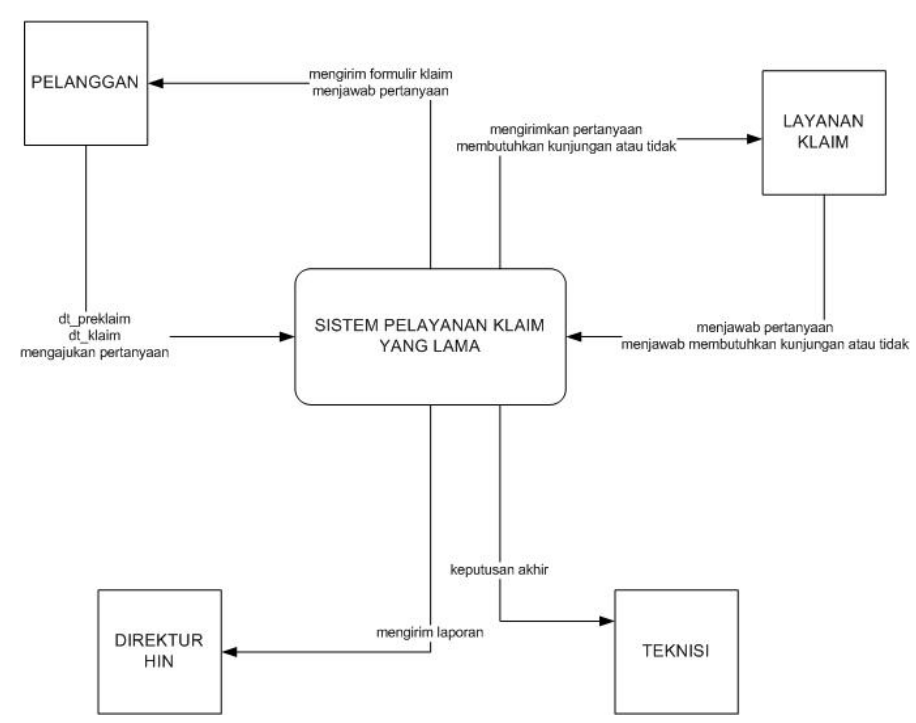

Gambar 2. DFD konteks sistem berjalan.

\section{Rancangan Sistem}

Dalam perancangan sistem ini penulis memutuskan untuk memakai metode perancangan inkremental dan dalam pembuatan basis data, penulis memutuskan untuk memakai teori Database Application Lifecycle.

Usulan pemecahan untuk permasalahan yang ada adalah sebagai berikut. Pertama, membuat web aplikasi yang akan mempermudah pelanggan untuk mengisi claim form secara on-line. Pelanggan juga bisa men-download claim form dalam format MS. Excel dari web-nya, sehingga dapat mengisinya, lalu meng-upload kembali ke web. Kedua, pelanggan yang ingin mengetahui perkembangan klaimnya dapat melihat langsung status dari klaim mereka secara online; apakah klaim mereka belum diproses, sedang diproses, maupun sudah diproses. Setiap perkembangan status dari klaim yang ada, juga akan menghasilkan notification yang akan dikirim ke e-mail pelanggan yang 
bersangkutan. Dengan adanya web aplikasi ini, pelanggan dapat melihat langsung status klaim mereka dan pegawai PT. Hoppecke Indonesia pun dapat melihat status klaim yang belum diproses, sedang diproses, ataupun yang sudah diproses. Ketiga, memberikan suatu kemudahan bagi pengguna web aplikasi ini, dalam proses pelayanan klaim yang tadinya masih berbasis fisik. Pemrosesan dari setiap klaim juga bisa dilakukan oleh admin PT. Hoppecke Indonesia secara online. Setiap klaim yang masuk akan dihitung ke database dan dapat dilihat statistiknya. Keempat, melakukan feedback dengan mengirimkan email ke pelanggan secara terstruktur. Dengan adanya pengaturan jadwal di web aplikasi ini, dapat memberikan kemudahan bagi pengguna, baik pelanggan, claim PIC, dan teknisi untuk mencocokkan jadwal, sehingga mempermudah dan mempercepat proses klaim. Kelima, membuat aplikasi BlackBerry ${ }^{\circledR}$ yang dapat diakses di mana saja dan kapan saja, sehingga dapat mempermudah dan mempercepat kinerja claim PIC dalam menyelesaikan klaim yang ada.

Usulan prosedur yang baru sebagai tambahan dari sistem yang sedang berjalan yaitu membuat sistem pelayanan klaim online interaktif berbasis web. Pelanggan dapat melakukan proses klaim melalui internet (tetapi masih juga menggunakan telepon karena sistem masih baru dan pelanggan ada yang belum mengetahui situs perusahaan). Pelanggan baru akan registrasi terlebih dahulu, lalu bisa melakukan login. Pelanggan baru dapat mengisi formulir klaim di web (jika melalui telepon, proses pengisian formulir akan dilakukan oleh Sales). Data akan diproses dan dimasukkan ke dalam basis data klaim. Pelanggan juga dapat mengetahui status klaimnya melalui web. Lalu, PIC (admin) akan menentukan apakah klaim ini membutuhkan kunjungan atau tidak (PIC biasanya langsung menelpon ke pelanggan).

Apabila keputusannya membutuhkan kunjungan, PIC akan mengatur waktu kunjungan teknisi ke tempat pelanggan. Lalu, teknisi akan melakukan investigasi secara langsung ke tempat klaim yang disebutkan, serta membuat keputusan apakah itu merupakan masalah baterai atau masalah sistemnya. Jika pelanggan tidak membutuhkan kunjungan (PIC sudah mengetahui secara garis besar klaim tersebut, lalu melakukan investigasi), PIC akan membuat keputusan apakah itu merupakan masalah baterai atau masalah sistemnya. Jika masalah pada sistem, PIC akan melakukan penjadwalan untuk repair/install baterai ke tempat klaim (melakukan repair/install produk PT. Hoppecke Indonesia di tempat klaim hingga tuntas). Jika masalah pada baterai, PIC melakukan penjadwalan untuk repair produk PT. Hoppecke Indonesia hingga tuntas. Berikut adalah class diagram yang diusulkan untuk sistem ini (Gambar 3).

\section{Hasil}

Dibawah ini beberapa tampilan aplikasi Blackberry untuk sistem manajemen klaim yang dirancang (Gambar 4 dan 5).

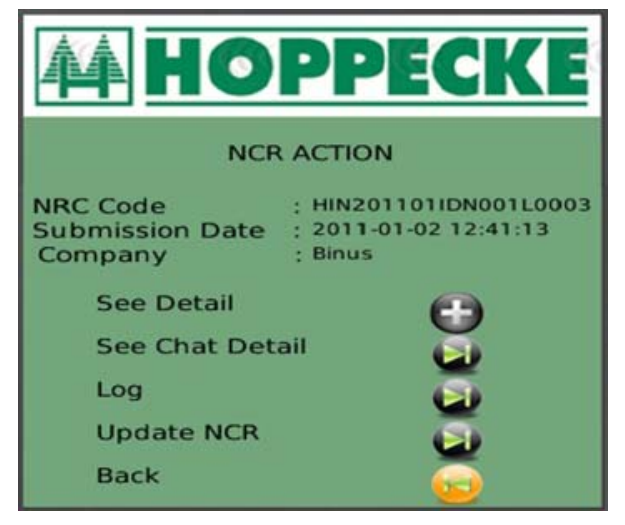

Gambar 4. Tampilan halaman NCR di layar Blackberry ${ }^{\circledR}$.

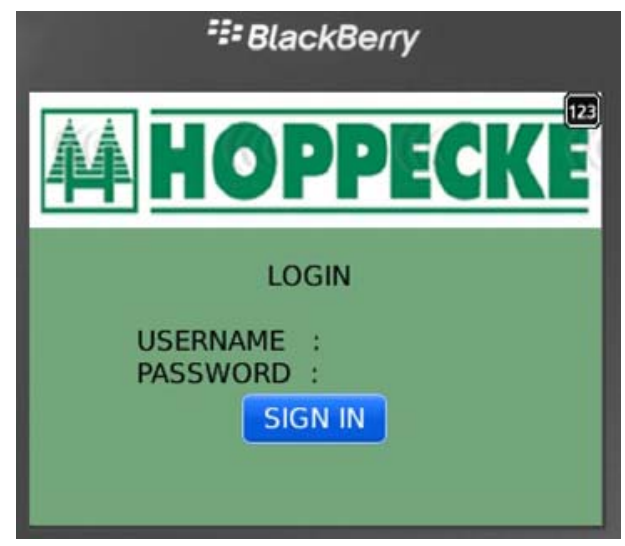

Gambar 5. Halaman masuk pada Blackberry ${ }^{\circledR}$ untuk admin. 


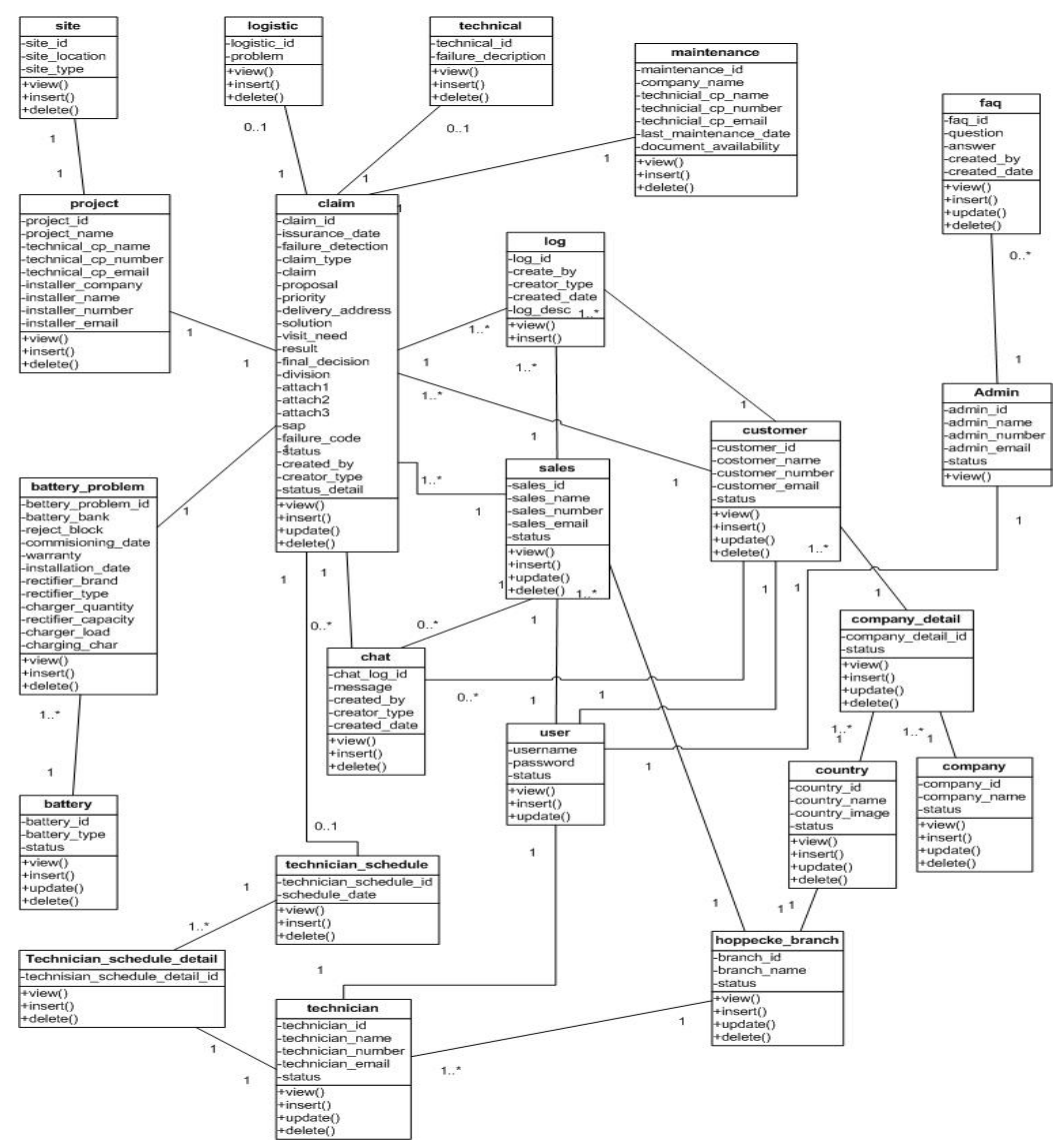

Gambar 3. Diagram kelas sistem yang diusulkan.

\section{PENUTUP}

Berdasarkan rancangan yang dibuat dapat diambil kesimpulan antara lain: (1) Dengan aplikasi web ini, bagian sales manajemen klaim secara langsung dapat langsung melayani pelanggan yang akan mengajukan klaim dengan cepat, hemat waktu, dan mengurangi kerugian perusahaan yang diakibatkan keterlambatan informasi; (2) Dengan aplikasi web ini, bagian teknisi secara langsung dapat mengetahui jadwal yang harus dikerjakan; (3) Dengan aplikasi web ini, pelanggan dengan mudah mendapatkan informasi tentang proses klaim mereka dan bisa berkomunikasi melalui chat; (4) Sistem manajemen klaim yang dirancang ini memperbaiki sistem manajemen klaim pada PT. Hoppecke Indonesia dengan melakukan integrasi yang baik dan tepat pada proses klaim sehingga dapat mempermudah dalam manipulasi data; (5) Sistem manajemen klaim yang dirancang ini membuat sistem menjadi lebih baik untuk mempermudah dalam pembuatan laporan, sehingga analisis dalam pengambilan keputusan manajerial menjadi lebih cepat dan akurat.

\section{DAFTAR PUSTAKA}

Connoly, T. dan C. Begg. (2005). Database System: A Practical Approach to Design, Implementation, and Management, ( $4^{\text {th }}$ ed.). Boston: Addison-Wesley. 
Pressman, Roger S. (2002). Rekayasa Perangkat Lunak Pendekatan Praktisi, (Buku Satu). Yogyakarta: Andi.

Turban, Efraim, Dorothy Leidner, Ephraim Mclean, dan James Wetherbe. (2006). Information Technology for Management: Transforming Organizations in the Digital Economy. Toronto: John Wiley and Sons. 